\title{
Advances in Pharmacology of Isatin and its Derivatives: A Review
}

\author{
Farhan A. Khan* and Aneela Maalik \\ Department of Chemistry, COMSATS Institute of Information Technology, Abbottabad-22060, KPK, Pakistan
}

*For correspondence: Email: farhankhan@ciit.net.pk; Tel: +92 334728 6986; Fax: +92 992383441

Received: 9 January 2015

Revised accepted: 29 August 2015

\begin{abstract}
Isatin (1H-indole-2,3-dione), an indole derivative of plant origin, is involved in many pharmacological activities like antiallergic, antimalarial, antiviral and antimicrobial; isatin and its derivatives have been found to show promising results against various cancer cell lines. Isatin is a versatile precursor for many biologically active molecules and its diversified nature makes it a versatile substrate for further modifications. This review provides a brief overview on the recent advances and future perspectives on pharmacological aspects of isatin and its derivatives reported in the last decade.
\end{abstract}

Keywords: Isatin, Anticancer, Antimicrobial, Monoamine oxidase, Antiviral

Tropical Journal of Pharmaceutical Research is indexed by Science Citation Index (SciSearch), Scopus, International Pharmaceutical Abstract, Chemical Abstracts, Embase, Index Copernicus, EBSCO, African Index Medicus, JournalSeek, Journal Citation Reports/Science Edition, Directory of Open Access Journals (DOAJ), African Journal Online, Bioline International, Open-J-Gate and Pharmacy Abstracts

\section{INTRODUCTION}

Isatin occurs in the leaves and roots of the Strobilanthes cusia (Nees) and was first isolated from plants of the Isatis tinctoria, Couroupita guianesis and Calanthe discolor in 1840 [1]. These plants are abundant in northern and central China and are of ethnic importance in traditional therapeutics. Despite of its presence in human brain isatin can also be found in secretion from the parotid glands of Bufo frogs and other biotic like; Caribbean tumorigenic plant, Melochia tomentosa, fungi and marine mollusks.

Isatin was first synthesized by Erdmann and Laurent in 1840 [2]. Isatin and triazole containing heterocyclic compounds are reported as a cure of lethal diseases [3]. Extensive literature has been published regarding the chemistry and medicinal importance of this compound including a few reviews [4]. Synthesis of isatin and its derivatives have gained great attention in recent years due to its biological potential like anticancer, anti-protozoa, cytotoxic and DNA cleavage.

In the literature, synthesis, reactivity and pharmacology of isatin have been extensively discussed but a brief account of pharmacological developments of isatin in the last decade is required. Current work is an effort to summarize the published pharmacological data of isatin and its derivatives.

\section{PHARMACOLOGICAL PROPERTIES OF ISATIN}

Isatin can be found in rat brain (mainly in hippocampus and cerebellum) as well as in other mammalian tissues where it functions as a modulator of biochemical processes [5]. Isatin and its derivatives have been reported highly 
efficient during in vitro studies against genotoxic and mutagenic diseases, but during in vivo, the genotoxic and mutagenic potential of isatin is not well established and reported. Isatin was first reported as "Tribulin" and was identified as a selective inhibitor of monoamine oxidase (MAO) [6]. Isatin shows a wide range of pharmacological activities reported in the literature, including antiviral [7], spermicidal [8], anti-corrosive [9], analgesic [10], anticonvulsant [11], antioxidant [12], antitubercular [13], transthyretin fibrillogenesis inhibitory activity [14], antidepressant [15] and antiepileptic [16] as shown (Figure 1). Some of the pharmacological activities exhibited by isatin are discussed in this review and are listed in (Table 1 ).

\section{Anti-asthmatic activity}

Asthma afflicts more than 235 million people worldwide annually [17]. Traditionally, a potent remedy for asthma is treatment by inhalation of drugs, containing corticosteroids and long-acting beta agonists; which reduce swelling and body immune response but these drugs can contribute to serious side effects [18]. Encapsulated isatin in chitosan nanoparticles has been reported effective against allergic asthma [19]. Moreover, respiratory synctial viral infections can be among the reasons of asthma in infants [20] while during in vitro and in vivo studies benzimidazole-isatin oxime derivatives have been described effective against respiratory synctial viral infection [21]. Therefore, a more comprehensive and targeted research is required to find out potential drug molecules against asthma from the isatin derivatives.

\section{Anticancer activity}

Isatin and its derivatives have been found effective against a variety of cancer cell lines [22-
23] and possess cytotoxic activity [24]. Cancer is a fast growing threat in the current century, therefore, new therapeutics are required to counter it [25]. During in vitro studies, 1,2,3triazole tethered isatin conjugates have been studied against human cancer cell lines i.e. PC3, A-549, Caco-2, and THP-1 using sulforhodamine B assay for anticancer activity, during research few derivatives have been reported to possess activity comparable to 5flouorouracil [26] while N-benzylisatin sulfonamide derivatives have been described as effective against caspase- 3 which is involved in apoptosis [27]. Recently, bis-Schiff base derivatives of isatin have been evaluated both for in vitro and in vivo potential and were reported for cytotoxic and antitumor activities especially against human lymphoma cells [28]. Moreover, benzothiazole derivatives of isatin have been reported to be effective against breast cancer cells [29]. In another study, isatin derivatives were evaluated in vitro against three human tumor cell lines, K562, HepG2 and HT-29 by using MTT assay, the studies suggested that the combination of 1-benzyl and 5-[trans-2(methoxycarbonyl) ethen-1-yl] substitution greatly enhances their cytotoxic potential, however, an intact carbonyl functionality on C-3 as present in the parent ring is required for such a potency [30]. A variety of isatin derivatives have been found active against various cancer cell lines, therefore, isatin has a potential for structural modifications in search of an anticancer molecule.

\section{Antimalarial activity}

In 2010, malaria epidemic caused the death 7 million children infected with Plasmodium falciparum, which is the main cause of malaria and has developed resistance against traditional

Table 1: Pharmacological activities of isatin

\begin{tabular}{|c|c|c|c|}
\hline $\mathbf{S} / \mathbf{N}$ & Activity & IUPAC names of Isatin derivatives & Reference \\
\hline 1 & Antiasthmatic activity & $\begin{array}{c}\text { (E)-1-((1-(4-fluorobutyl)-1H-benzo[d]imidazol-2-yl)methyl) } \\
\text {-3-(hydroxyimino)indolin-2-one }\end{array}$ & {$[17-21]$} \\
\hline 2 & Anticancer activity & 3,3-bis(4-hydroxyphenyl)indolin-2-one & {$[22-30]$} \\
\hline 3 & Antimalarial activity & $\begin{array}{c}\text { 1-(4-(4-((4-(2-(7-chloroquinolin-4-yl)hydrazinyl)phenoxy)methyl) } \\
\text {-1H-1,2,3-triazol-1-yl)butyl)-3-hydroxyindolin-2-one }\end{array}$ & [31-33] \\
\hline 4 & $\begin{array}{l}\text { MOA-inhibition } \\
\text { activity }\end{array}$ & 5-(Benzyloxy)indoline-2,3-dione & [34-36] \\
\hline 5 & Antiviral activity & $\begin{array}{l}\text { (Z)-1-((1-isopentyl-1H-benzo } \\
\text { [d]imidazol-2-yl)methyl)-3- } \\
\text { (methoxyimino)indolin-2-one }\end{array}$ & [37-39] \\
\hline 6 & Antimicrobial activity & $\begin{array}{c}\text { (R)-2'-amino-6'-(1H-indol-3-yl)-2-oxospiro[indoline-3,4'-pyran]- } \\
\text { 3',5'-dicarbonitrile }\end{array}$ & {$[40-44]$} \\
\hline
\end{tabular}


<smiles>O=C1/C(=N/OP)c2ccccc2N1Cc1nc2ccccc2n1CCCCF</smiles>

(E)-1-((1-(4-Fluorobutyl)-1H-benzo[d]imidazol -2-yl)methyl)-3-(hydroxyimino)indolin-2-one Antiasthamatic [21]<smiles>O=C1Nc2ccccc2C1(c1ccc(O)cc1)c1ccc(O)cc1</smiles>

3,3-Bis(4-hydroxyphenyl)indolin-2-one Anticancer [23]<smiles>CO/N=C1\C(=O)N(Cc2nc3ccccc3n2CCC(C)C)c2ccccc21</smiles>

(Z)-1-((1-Isopentyl-1H-benzo[d]imidazol-2-yl) methyl)-3-(methoxyimino)indolin-2-one Antiviral [37]

Figure 1: Pharmacologically active Isatin derivatives

treatment of chloroquine, cycloguanil and pyrimethamine due to gene mutation; in vitro studies conducted on Plasmodium falciparum W2 strain, triazole and substituted indole derivatives of isatin have been stated as effective antimalarial agents [31]. Moreover, carbodithioate 2,3-dioxoindoline derivatives of<smiles></smiles>

1-(4-(4-((4-(2-(7-Chloroquinolin-4-yl)hydrazinyl)phenoxy) methyl)-1 $H$-1,2,3-triazol-1-yl)butyl)-3-hydroxyindolin-2-one Antimalarial [31]<smiles>O=C1Nc2ccc(OCc3ccccc3)cc2C1=O</smiles>

5-(Benzyloxy)indoline-2,3-dione MAO-inhibitor [36]<smiles>N#CC1=C(N)OC(c2c[nH]c3ccccc23)=C(C#N)[C@]12C(=O)Nc1ccccc12</smiles>

(R)-2'-Amino-6'-(1H-indol-3-yl)-2-oxospiro [indoline-3,4'-pyran]-3',5'-dicarbonitrile Antimicrobial [43]

isatin have also been described to show antimalarial activity against Plasmodium falciparum [32]. Recently, organometallic derivatives consisting of isatin-ferrocene conjugates have been reported for their antimalarial potential against chloroquineresistant (W2) strain. [33]. 


\section{MAO-inhibition activity}

Monoamine oxidase (MAO) is a class of enzymes, which catalyzes the oxidation of serotonin and norepinephrine by utilizing dopamine as substrate; MAO activity in human brain increases with age and can cause neurodegenerative disorders such as Parkinsons disease [34]. Synthesis and evaluation of MAO inhibitors is an active area of research and isatin has been reported to be a reversible inhibitor of MAO isozyme [35]. Moreover, isatin derivatives with substitution at position $\mathrm{C} 5$ and $\mathrm{C} 6$ are reversible inhibitors of MAO-(A and $B)$, these substitutions can potentially affect the binding affinities; however, C5- and C6-benzyloxy substituted isatin derivatives have been reported as MAO-B inhibitors with $\mathrm{IC}_{50}$ of $0.103 \mu \mathrm{M}$ and $0.138 \mu \mathrm{M}$ respectively [36].

\section{Antiviral activity}

Isatin shows a good potential against a variety of viruses. During in vitro studies, isatinoxime ethers have been reported for their cytotoxicity and inhibitory activity against Respiratory Syncytial Virus (RSV), which produces infection in children under 2 years of age and may causes death [37]. During, in vitro studies, 5-fluoroisatin derivatives have been described to show good inhibitory activity on Vero clone CCL-81 cells pretreated with vesicular stomatitis virus [38]. Recently, substituted hydrazine derivatives of isatin are stated to have good antiviral potential against Coxsackie virus $\mathrm{B} 3$, which is a primary cause of viral myocarditis and results in sudden death, one of the derivatives ID45 has been reported to show good potential for reduction of viral growth, it also hampers the process of virusinduced apoptosis [39].

\section{Antimicrobial activity}

Isatin analogues are important due to their therapeutic potential against a variety of pathogenic microbes. In a study, thiosemicarbazone and dispiropyrrolidine derivatives of isatin have been reported to inhibit the growth of Mycobacterium tuberculosis [4041]. During in vitro studies, isatin-3phenylhydrazone has been described to show more antimicrobial activity against Proteus vulgaris, Proteus aeruginosa, Escherichia coli, Pseudomonas aeruginosa and Staphylococcus aureus than the reference compounds amoxicillin and norfloxacin [42]. Moreover, one-pot synthesis of spiroxindoles derived from isatin has been reported to exhibit good and moderate antimicrobial activity against various bacterial and fungal strains [43]. However, metal complexes of lanthanides have been reported to increase the antifungal potential of isatin bishydrazones by affecting various factors including lipophilicity of the molecule [44].

\section{CONCLUSION}

Isatin is a synthetically versatile molecule with a diversified nature of pharmacological applications. The focus of the review was to summarize the recent literature published about isatin and its derivatives. These heterocyclic molecules are among the fastest developing areas of interest for synthetic chemists and pharmacists. We have discussed some of the properties including, antiasthamatic, anticancer, MOA-inhibitor, antiviral and antimicrobial, however, as mentioned earlier, isatin derivatives have good potential and a broad spectrum of application against various cancer cell lines, therefore, synthesis and investigation of new isatin derivatives is an active area of research and has the potential for the development of pharmacologically active molecules.

\section{ACKNOWLEDGEMENT}

The authors acknowledge Higher Education Commission (HEC) of Pakistan for providing literature facilities for this work.

\section{REFERENCES}

1. Gang Cl, Hui-jun S, Min Zhang1, Fang H, Zhang J, Xiaojiang $H$, Jing-rui $Z$. New bactericide derived from Isatin for treating oilfield reinjection water. Chem Central J. 2012; 6: 90-94.

2. Candido-Bacani PD, Reis BD, Serpeloni JM, Calvo TR, Vilegas $W$, Varanda EA, Colus IMD. Mutagenicity and genotoxicity of isatin in mammalian cells in vivo. Mutat Res. 2011; 719: 47-51.

3. Bekircan O, Hakan B. Synthesis of Schiff and Mannich bases of isatin derivatives with 4-amino-4,5-dihydro-1H1,2,4-triazole-5-ones. Molecules. 2008; 9: 2126-2135.

4. Joaquim FM, da Silva, Simon J, Garden, Angelo CP. The Chemistry of Isatins: a Review from 1975 to 1999. J Braz Chem Soc. 2001; 3: 273-324.

5. Hou L, Ju CX, Zhang JY, Song JL, Ge YL, Yue W. Antitumor effects of Isatin on human neuroblastoma cell line (SH-SY5Y) and the related mechanis. Eur $J$ Pharmacol. 2008; 589: 27-31.

6. Gang $C$, Wang $Y$, Xiaojiang $H$, Shuzhen $M$, Qianyun $S$. Simple isatin derivatives as free radical scavengers: Synthesis, biological evaluation and structure-activity relationship. Chem Cent J. 2011; 5: 37-41. 
7. Kang IJ, Wang LW, Hsu TA, Yueh A, Lee CC, Lee YC. Isatin-beta-thiosemicarbazones as potent herpes simplex virus inhibitors. Bioorg Med Chem Lett. 2011; 21: 1948-1952.

8. Paira P, Hazra A, Kumar S, Paira R, Sahu KB, Naskar S, Saha $P$, Mondal S, Maity A, Banerjee S, Mondal NB. Efficient synthesis of 3,3-diheteroaromatic oxindole analogues and their in vitro evaluation for spermicidal potential. Bioorg Med Chem Lett. 2009; 19: 4786-4789.

9. Quraishi MA, Ahamad I, Singh AK, Shukla SK. N(Piperidinomethyl)-3-[(pyridylidene)amino]isatin: $A$ new and effective acid corrosion inhibitor for mild steel. Mater Chem Phys. 2008; 3: 1035-1039.

10. Figueiredo GS, Zardo RS, Silva BV, Violante FA, Pinto $A C$, Fernandes $P D$. Convolutamydine $A$ and synthetic analogues have antinociceptive properties in mice. Pharmacol Biochem B. 2013; 3: 431-439.

11. Nagihan B, Kocyigit-Kaymakcioglu B, Salih G, Aricioglu $F$. Synthesis and anticonvulsant activity of some 2pyrazolines derived from chalcones. Arab $\mathrm{J}$ Chem. http://dx.doi.org/10.1016/j.arabjc.2013.07.037.

12. Andreani A, Burnelli S, Granaiola M, Leoni A, Locatelli A, Morigi R, Rambaldi M, Varoli L, Cremonini MA, Plaucci $G$, Cervellati R, Greco E. New isatin derivatives with antioxidant activity. Eur J Med Chem. 2010; 45: 1374 1378.

13. Kumar K, Carrere-Kremer S, Kremer L, Guerardel Y, Biot C, Kumar V. 1H-1,2,3-triazole-tethered isatin-ferrocene and isatin-ferrocenylchalcone conjugates: synthesis and in Vitro antitubercular evaluation. Organometallics. 2013; 32: 110-116.

14. Gonzalez A, Quirante J, Nieto J, Almeida MR, Saraiva MJ, Planas $A$, Arsequell $G$, Valencia $G$. Isatin derivatives, a novel class of transthyretin fibrillogenesis inhibitors. Bioorg Med Chem Lett. 2009; 19: 5270-5273.

15. Manley-King Cl, Bergh JJ, Petzer JP. Inhibition of monoamine oxidase by selected C5- and C6-substituted isatin analogues. Bioorg Med Chem. 2011; 19: 261-274.

16. Prakash CR, Raja S. Design, synthesis and antiepileptic properties of novel 1-(substituted benzylidene)-3-(1(morpholino/piperidino methyl)-2,3-dioxoindolin-5yl) urea derivatives. Eur J Med Chem. 2011; 46: 6057 6065.

17. Harvey RA. Lippincott's illustrated reviews: Pharmacol. 5th edition 2012; p. 339-350.

18. Townley RG, Suliaman F. The mechanism of corticosteroids in treating asthma. Annals Allergy 1987; 58: 1-6

19. Kandasamy R, Park SJ, Boyapalle S, Mohapatra S, Hellermann GR, Lockey RF, Mohapatra SS. Isatin down-regulates expression of atrial natriuretic peptide receptor $A$ and inhibits airway inflammation in a mouse model of allergic asthma. Int Immunopharmacol. 2010; 10: 218-225.

20. Wu P, Hartert TV. Evidence for a causal relationship between respiratory syncytial virus infection and asthma. Expert Rev Anti-infective Therapy 2011; 9: 731 . 745 .
21. Sin $N$, Venables $B L$, Combrink $K D$, Gulgeze $H B$, Yu $K L$, Civiello RL, Thuring J, Wang $X A$, Yang $Z$, Zadjura $L$, Marino A, Kadow KF, Cianci CW, Clarke J,Genovesi EV, Medina I, Lamb L, Krystal M, Meanwell NA. Respiratory syncytial virus fusion inhibitors. Part 7: Structure-activity relationships associated with a series of isatin oximes that demonstrate antiviral activity in vivo. Bioorg Med Chem Lett. 2009; 19: 4857-4862.

22. Ashraf HA, Abou-Seri SM, Abdel-Rahman DE. Christian $K$, Lozach O, Laurent M. Synthesis of 3-substituted-2oxoindole analogues and their evaluation as kinase inhibitors, anticancer and antiangiogenic agents. Eur $\mathrm{J}$ Med Chem. 2006; 3: 296-305.

23. Uddin MK, Reignier SG, Coulter T, Montalbetti C, Grånäs C, Butcher S, Krog-Jensen C, Felding J. Syntheses and antiproliferative evaluation of oxyphenisatin derivatives. Bioorg Med Chem Lett. 2007; 10: 2854-2857.

24. Matesic L, Locke JM, Bremner JB, Stephen GP, Skropeta $D$, Ranson $M$, Vine $K L$. N-phenethyl and $N$ naphthylmethyl isatins and analogues as in vitro cytotoxic agents. Bioorg Med Chem. 2008; 6: 31183124.

25. Jemal A, Siegel R, Ward E, Hao Y, Xu J, Murray T, Thun MJ. Cancer statistics, 2008. CA Cancer J Clin. 2008; 2: 71-96.

26. Singh $P$, Sharma $P$, Anand A, Bedi PMS, Kaur T, Saxena AK, Kumar V. Azide-alkyne cycloaddition en route to novel $1 \mathrm{H}-1,2,3-$ triazole tethered isatin conjugates with in vitro cytotoxic evaluation. Eur J Med Chem. 2012; 55: 455-461.

27. Chu W, Zhang J, Zeng C, Rothfuss J, Tu Z, Chu Y, Reichert DE, Welch MJ, Mach RH. N-benzylisatin sulfonamide analogues as potent caspase-3 inhibitors: synthesis, in vitro activity, and molecular modeling studies. J Med Chem. 2005; 24: 7637-7647.

28. Liang C, Xia J, Lei D, Li X, Yao Q, Gao J. Synthesis, in vitro and in vivo antitumor activity of symmetrical bisSchiff base derivatives of isatin. Eur J Med Chem. 2014; 74: 742-750.

29. Solomon VR, Hu CK, Lee H. Hybrid pharmacophore design and synthesis of isatin-benzothiazole analogs for their anti-breast cancer activity. Bioorg Med Chem. 2009; 17(21): 7585-7592.

30. Han K, Zhou Y, Liu F, Guo Q, Wang P, Yang Y, Song B, Liu $W$, Yao $Q$, Teng $Y, Y u P$. Design, synthesis and in vitro cytotoxicity evaluation of 5-(2-carboxyethenyl)isatin derivatives as anticancer agents. Bioorg Med Chem Lett. 2014; 24: 591-594.

31. Raj R, Gut J, Rosenthal PJ, Kumar V. 1H-1,2,3-triazoletethered isatin-7-chloroquinoline and 3-hydroxy-indole7-chloroquinoline conjugates: Synthesis and antimalarial evaluation. Bioorg Med Chem Lett. 2014; 24: 756-759.

32. Tarunkumar NA, Jignesh PR. New carbodithioate derivatives: synthesis, characterization, and in vitro antibacterial, antifungal, antitubercular, and antimalarial activity. Med Chem Res. 2013; 22(10): 4700-4707.

33. Kumar K, Pradines B, Madamet M, Amalvict R, Benoit $N$,

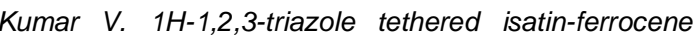

Trop J Pharm Res, October 2015; 14(10): 1941 
conjugates: Synthesis and in vitro antimalarial evaluation. Eur J Med Chem 2014; 87: 801-804.

34. Ogata A, Hamaue N, Terado M, Minami M, Nagashima K, Tashiro K. Isatin, an endogenous MAO inhibitor, improves bradykinesia and dopamine levels in a rat model of Parkinson's disease induced by Japanese encephalitis virus. J Neurol Sci. 2003; 1: 79-83.

35. Chiaki I. Enzyme inhibitors of marine microbial origin with pharmaceutical importance. Marine Biotech. 2004; 3 : 193-198.

36. Manley-King Cl, Bergh JJ, Petzer JP. Inhibition of monoamine oxidase by C5-substituted phthalimide analogues. Bioorg Med Chem. 2011; 19(16): 48294840.

37. Sin $N$, Venables $B L$, Combrink $K D$, Gulgeze $H B, Y u K L$, Civiello RL, Thuring J, Wang XA, Yang $Z$, Zadjura $L$, Marino A, Kadow KF, Cianci CW, Clarke J,Genovesi EV, Medina I, Lamb L, Krystal M, Meanwell NA. Respiratory syncytial virus fusion inhibitors. Part 7: Structure-activity relationships associated with a series of isatin oximes that demonstrate antiviral activity in vivo. Bioorg Med Chem Lett. 2009; 19: 4857-4862.

38. Abbas SY, Farag AA, Ammar YA, Atrees AA, Mohamed $A F$, El-Henawy $A A$, Synthesis, characterization, and antiviral activity of novel fluorinated isatin derivatives. Monatshefte Für Chemie. 2013, 144, 1725-1733.

39. Zhang HM, Dai $H$, Hanson PJ, Li $H$, Guo $H$, Ye $X$, Hemida MG, Wang L, Tong $Y$, Qiu $Y$, Liu S, Wang $F$,
Song F, Zhang B, Wang JG, Zhang LX, Yang D. Antiviral activity of an isatin derivative via induction of PERKNrf2-mediated suppression of cap-independent translation. ACS Chem Biol 2014; 9: 1015-1024.

40. Banerjee $D$, Yogeeswari $P$, Bhat $P$, Thomas $A$, Srividya $M$, Sriram $D$. Novel isatinyl thiosemicarbazones derivatives as potential molecule to combat HIV-TB coinfection. Eur J Med Chem. 2011; 46(1): 106-121.

41. Kumar RS, Rajesh SM, Perumal S, Banerjee D, Yogeeswari $P$, Sriram $D$. Novel three-component domino reactions of ketones, isatin and amino acids: synthesis and discovery of antimycobacterial activity of highly functionalised novel dispiropyrrolidines. Eur J Med Chem. 2010; 45(1): 411-422.

42. Konstantinović SS, Kapor A, Radovanović BC, Deak A, Synthesis, X-ray and antimicrobial activity of isatin-3phenylhydrazone, Chem Ind Chem Eng Quart. 200814 (1), 27-34.

43. Nandakumar $A$, Thirumurugan $P$, Perumal $P T$, Vembu $P$, Ponnuswamy MN, Ramesh P. One-pot multicomponent synthesis and anti-microbial evaluation of 2'-(indol-3-yl)-2-oxospiro(indoline-3,4'-pyran) derivatives. Bioorg Med Chem Lett. 2010; 14: 42524258.

44. Mohanan K, Sindhu K, Rijulal G. Microwave assisted synthesis, spectroscopic, thermal, and antifungal studies of some lanthanide(III) complexes with a heterocyclic bishydrazone. J Rare Earths. 2008; 26(1): 16-21. 